\title{
Tragédia sem redenção: o pessimismo absoluto de Julius Bahnsen*
}

\author{
Tragedy without redemption: the absolute pessimism of Julius \\ Bahnsen
}

\author{
Flamarion Caldeira Ramos \\ Doutor em Filosofia pela USP \\ Professor de ética da Universidade Federal do $A B C$ \\ E-mail: flamarioncr@yahoo.com.br
}

Resumo: Trata-se neste texto de apresentar a filosofia de Julius Bahnsen (1830-1881), cuja teoria é uma tentativa de conciliar a filosofia da vontade de Schopenhauer com a dialética de Hegel, o que resultou na elaboração de uma dialética real (Realdialektik), uma espécie de pessimismo absoluto. Para essa apresentação será enfatizada a concepção do trágico como uma categoria não apenas restrita à reflexão estética, mas como própria da manifestação da contradição inerente à vontade, a qual ao mesmo tempo quer e não quer. Ao invés de propor alguma saída redentora para o círculo autocontraditório da vontade, Bahnsen afirmará o caráter irreconciliável dessa cisão e rejeitará a perspectiva soteriológica da filosofia schopenhaueriana defendida por Eduard von Hartmann e Philipp Mainländer. O resultado será um decidido niilismo que encontrará apenas na categoria do humor uma possibilidade de alívio.

Palavras-chave: Tragédia; Redenção; Pessimismo; Humor.
Abstract: This paper aims at expose and debating the thought of german philosopher Julius Bahnsen (1830-1881), whose theory is an attempt at reconciling Schopenhauer's theory of the will with Hegel's dialectics, a kind of "real dialectics" (Realdialektik) and absolute pessimism. For this presentation the conception of tragic will be emphasized as a category not only restricted to aesthetic reflection, but as itself the manifestation of the contradiction inherent in the will, which both want and do not want. Rather than propose some redeeming way out of the circle of self-contradictory will, Bahnsen states the unforgiving nature of this split and reject the salvific perspective of Schopenhauer's philosophy advocated by Eduard von Hartmann and Philipp Mainländer. The result will be decided nihilism that find only in the category of humor a possibility of relief.

Keywords: Tragedy; Redemption; Pessimism; Humor.

\footnotetext{
* O texto que se segue é parte do resultado de um estágio de pesquisa no Centro interdipartimentale di ricerca su Arthur Schopenhauer e la sua scuola da Universidade de Salento (Lecce/ltália) financiado pela Fapesp. Agradeço aos professores Domenico Fazio e Fabio Ciracì pelo acolhimento em Lecce e pela colaboração com a pesquisa.
} 
“Jusqu'à M. Bahnsen, II ne s'est point trouvé de pessimisme absolu: tous ont fait ce rêve que la misère universelle prendrait fin" (A. Burdeau, Revue philosophique, III, 5 -1878).

\section{A escola de Schopenhauer}

ulius Bahnsen (1830-1881) certamente não é dos mais célebres dos já
bem obscuros autores do chamado pessimismo filosófico alemão do
século XIX. Sua obra teve, salvo engano, sua primeira tradução publicada somente neste ano na Espanha' ${ }^{1}$. A contribuição de Bahnsen é original, na medida em que pretendeu oferecer modificações essenciais à filosofia de Schopenhauer, e por outro lado, incorporou elementos importantes da filosofia de Hegel, especialmente o conceito de contradição, o qual ele também submete a uma nova modificação.

Os estudos de Domenico Fazio e do Centro interdipartimentale di ricerca su Arthur Schopenhauer e la sua scuola da Universidade de Salento (Lecce/ltália) sobre o conceito Schopenhauer-Schule estabeleceram a importante distinção entre a escola schopenhaueriana em sentido estrito e a escola schopenhaueriana em sentido amplo. Ao primeiro grupo pertencem aqueles que formavam aquilo que o próprio Schopenhauer considerava a sua escola ${ }^{2}$, composta por quem teve uma relação direta com ele de colaboração e se apresentavam como seus discípulos. Ao segundo grupo pertencem aqueles que depois da morte do filósofo, em 1860, desenvolveram obras inspiradas em sua filosofia em diversas direções: seja construindo novas metafísicas baseadas nos fundamentos da doutrina schopenhaueriana, seja desenvolvendo em direções originais um ou outro aspecto particular de seu pensamento, seja trabalhando no âmbito da pesquisa sobre o pensamento de Schopenhauer fixando, difundindo ou defendendo seus princípios, em suma, todos aqueles que se disseram schopenhauerianos ou foram considerados schopenhauerianos ${ }^{3}$.

Curiosamente, o nome de Julius Bahnsen pode ser contado tanto entre os membros da escola schopenhaueriana em sentido estrito, quanto entre aqueles da

\footnotetext{
1 Cf. BAHNSEN, J. Lo trágico como ley del mundo y el humor como forma estética de lo metafísico. Tradução de Manuel Pérez Cornejo. Universitat de València, 2015.

2 Numa carta de 10/01/1855 Schopenhauer escreve a Adam von Doss por ocasião da morte de Friedrich Dorguth: "A escola acaba de sofrer uma perda dolorosa: o protoevangelista Dorguth morreu aos setenta e sete anos de cólera" (SCHOPENHAUER, A. Gesammelte Briefe, carta n. 351, p. 359). 3 Cf. FAZIO, D. La scuola di Schopenhauer: $i$ contesti, pp. 15-16
} 
escola em sentido amplo. Isso porque, de fato, Bahnsen visitou o filósofo em Frankfurt no verão de $1856{ }^{4}$, decidindo então se dispor a divulgar sua filosofia, criar uma revista em sua homenagem e fazer uma conferência em Hamburgo sobre sua doutrina. Bahnsen teria mesmo escrito, seguindo uma sugestão do próprio Schopenhauer, um texto sobre sua filosofia da matemática ${ }^{5}$. Eles chegaram a trocar correspondência e, segundo o relato de Bahnsen, o mesmo teria sido comparado ao "arquievangelista" Frauenstädt, no que diz respeito ao conhecimento de sua obra ${ }^{6}$.

Contudo, embora tenha de fato se apresentado como discípulo de Schopenhauer, Bahnsen desenvolveu na sequência uma filosofia original e própria, se referindo a outras fontes além da doutrina do autor de $O$ mundo como vontade $e$ representação. Embora, como já dito, num primeiro momento Bahnsen decida se tornar um estudioso e divulgador do pensamento de Schopenhauer, seu desenvolvimento o conduzirá a um prosseguimento autônomo que no final resultará numa filosofia bastante diferente. Em seu primeiro livro realmente importante, as Contribuições à caracterologia de 1867, embora Bahnsen ainda se declare schopenhaueriano, já se observa importantes afastamentos em relação à doutrina de O mundo como vontade e representação. Devido ao seu trabalho como educador em Lauenburg, Bahnsen pensa sobretudo na questão prática ao fazer o que ele mesmo qualifica como uma "fenomenologia da vontade", e dessa forma relaciona sua análise do caráter às questões pedagógicas. Já aqui a vontade de viver é compreendida como uma força individual e, apesar do materialismo, Bahnsen procura suavizar o estrito determinismo schopenhaueriano e aprofundar a noção de individualidade que o próprio Schopenhauer havia deixado incompleta. Articular uma teoria do caráter que dê conta da unidade e, portanto, da identidade essencial da vontade, por um lado, e, por outro, do aspecto necessariamente individual do caráter, é uma dificuldade que o próprio Schopenhauer confessa. É assim que num texto tardio ele reconhece não ter resolvido adequadamente o problema da

\footnotetext{
4 A descoberta da filosofia de Schopenhauer em 1853 é descrita por Bahnsen como um "acontecimento epocal". Após visitá-lo em Frankfurt no verão de 1856, Bahnsen se declara inteiramente convertido: "Saí de lá com a consciência não apenas de ter estado cara a cara com um gênio do pensamento, mas também com um caráter da mais bela sublimidade (...), assim me senti lançado a uma nova existência - aspirando à santidade do Nirvana" (BAHNSEN, J. Wie ich wurde was ich ward. Nebst anderen Stùcken aus dem Nachlass des Philosophen, p. 47).

5 Cf. BAHNSEN, J. Arthur Schopenhauer's Urtheil über den Bildungswerth der Mathematik. Schulzeitung fùr die Herzogtumer Schleswig, Holstein und Lauenburg", 1857, n. 21, 25, 26 (24.2, 21-28.3). Cf. INVERNIZZI, G. Il pessimismo tedesco dell'Ottocento. Schopenhauer, Hartmann, Bahnsen e Mainländer e i loro avversari, p. 210.

6 Cf. INVERNIZZI, G. Il pessimismo tedesco dell'Ottocento. Schopenhauer, Hartmann, Bahnsen e Mainländer e i loro avversari, p. 209; cf. FAZIO, D. La scuola di Schopenhauer: i contesti, p. 214.
} 
individualidade: "a individualidade não repousa unicamente no principio individuationis e não é, portanto, inteiramente apenas fenômeno, mas enraíza-se na coisa-em-si, na vontade do indivíduo, pois seu próprio caráter é individual. Até onde vai a profundidade de suas raízes constitui uma das questões cuja resposta eu não empreendo" 7 .

O longo livro sobre a Caracterologia já indicava a centralidade da questão do caráter e da individualidade na metafísica da vontade e na dialética real de Bahnsen. Seu sistema, porém, só será exposto de forma completa na obra Der Widerspruch im Wissen und Wesen der Welt, completada apenas no fim da vida e cujo primeiro volume será publicado poucos meses antes da morte do autor (o segundo será publicado postumamente em 1882). Em escritos menores, porém, o autor já esboça algumas características da sua "dialética do real". Em 1877 Bahnsen publica Das Tragische als Weltgesetz und der Humor als ästhetische Gestalt des Metaphysischen, obra que procura reformular sua tese de doutorado (apresentada na Universidade de Tübingen sob a orientação de Vischer) agora enriquecida com a influência da filosofia de Schopenhauer e o desenvolvimento da Realdialektik.

Julius Bahnsen pretende desdobrar aquilo que ele considera como as principais contribuições de Hegel e Schopenhauer: a dialética hegeliana da contradição e a metafísica schopenhaueriana da Vontade. Segundo Banhsen, elas seriam complementares porque o caráter exclusivamente espiritual e abstrato seria o defeito fundamental da dialética hegeliana, enquanto a ausência de uma compreensão dos processos temporais seria a principal deficiência da filosofia de Schopenhauer. A primeira se transfigura numa dialética do real que pretende ir além do panlogismo hegeliano ao compreender a contradição não como momento dentro de um percurso especulativo que teria em vista a reconciliação dos opostos, mas apreendê-la como inerente às coisas mesmas, enquanto a segunda se transforma num pluralismo trágico da vontade em que a noção de redenção desaparece. Para desenvolver a dialética do real, Bahnsen expõe um sistema complexo em que articula, por um lado, uma ontologia e uma filosofia da natureza e por outro, uma ética e uma escatologia moral, paralela a uma estética que tem no humor seu

7 SCHOPENHAUER, A. Sobre a ética, p. 71.

8 Primeiro num pequeno opúsculo de 1870 chamado Zum Verhältnis zwischen Wille und Motiv. Eine metaphysische Voruntersuchung zur Charakterologie. Neste livro, Bahnsen compara seu desenvolvimento com a Filosofia do inconsciente de Hartmann. Entretanto, após um breve período de amizade e colaboração, Bahnsen rompe com Hartmann e escreve uma dura crítica no livro Zur Philosophie der Geschichte: eine kritische Besprechung des HegelHartmann'schen Evolutionismus aus Schopenhauer'schen Principien (1872). 
conceito fundamental.

Assim como Mainländer, que procurou desenvolver um pluralismo da vontade a partir da filosofia de Schopenhauer, Julius Bahnsen também tentou resolver o problema da individualidade por meio de uma metafísica pluralista da vontade. Para ele, a essência dos seres do mundo pode ser compreendida como "seres volitivos" cujo "ens volens idemque nolens" não consistiria apenas em seguir direções diametralmente opostas, mas carregar em si próprios um "conteúdo que se contradiz a si mesmo". Trata-se, como Bahnsen escreve da "metafísica negatividade real de uma vontade que tanto quer como não quer" (metaphysische[n] Realnegativitat eines Willens, der ebensosehr will als nicht Will) e é ao mesmo tempo "voluntas nolens e noluntas volens".

Tudo se passa como se para Bahnsen a irracionalidade da vontade, já anunciada por Schopenhauer fosse radicalizada por meio de uma dialética. A própria concepção da vontade é a de algo contraditório, alógico, que consiste em querer e não querer ao mesmo tempo. A individualidade é compreendida como a expressão dessa contradição, como uma "concreção inconciliável de sim e não"10. O essencial da autocontradição da vontade se expressa no seu movimento paradoxal de oscilação entre o querer e o não querer:

Poder fazer somente uma coisa quando se quer fazer ambas é a implacável lei que impõe a realidade, e que dá seu conteúdo a todos os monólogos trágicos. Aquele que com plena consciência está em uma situação na qual tem que dar um passo que, entretanto, a partir do ponto de vista de sua própria consciência, não pode admitir, mostra uma unidade de querer e não-querer em seu eu mais íntimo que resume por si só toda a dialética real. Neste ponto se conjugam a mais clara autocondenação ética com o caráter insuperável dos motivos que se opõem ao "melhor eu", precisamente porque tais motivos não são em absoluto algo estritamente injustificável, mas são antes, por assim dizer, apenas os poderes e direitos da matéria que arrastam com violência para baixo a parte material do indivíduo derrubando-a das alturas do éter da idealidade. Igual ao corpo que se vê impedido pela terra em seu movimento de gravitação prolonga seu peso transformando-o em pressão, nessa vontade se mantém a contradição dinâmica, mesmo depois de ter feito a eleição e ter executado o ato correspondente ${ }^{11}$.

9 BAHNSEN, J. Das Tragische und der Humor, p. 6.

10 "Der Wille will, was er nicht will, und nicht will, was er Will" (BAHNSEN, J. Der Widerspruch im Wissen und Wesen der Welt. Princip und Einzelbewahrung der Realdialektik, vol. I, p. 53).

11 BAHNSEN, J. Das Tragische als Weltgesetz und der Humor als ästhetische Gestalt des Metaphysischen, p. 14). 
Para desenvolver uma dialética a partir dessa concepção de vontade, Bahnsen pretende desvinculá-la daquilo que ele considera ser uma concepção logicista como a de Hegel, que ele qualifica como mera "dialética verbal", centrada na progressão do conceito. A dialética do real pretende apresentar o curso do processo real do mundo. Antes de ser uma construção conceitual, a dialética do real tem a pretensão de ser um empirismo receptivo, isto é, não é o ser que tem que se orientar pelo pensamento, mas o padrão de medida deve ser dado pelo ser enquanto querer. Ao contrário de Hegel, Bahnsen reconhece uma oposição entre leis da realidade e leis do pensamento. Essa incompatibilidade de duas legislações, uma em relação à outra, conduz a conflitos constantes e revela um indivíduo pensante e querente como "colisão" de duas legislações diferentes. Apenas a lógica é capaz de "suprimir" ou "superar" essa contradição, mas isso é possível apenas in abstrato, no domínio do efetivo (tal como concebido por Bahnsen) a contradição permanece: "a lógica é senhora apenas no distrito do abstrato"12.

Por meio da contradição que atravessa o mundo, a vontade única postulada por Schopenhauer se dilacera em uma multiplicidade de vontades individuais. Tudo se passa como se a dialética real de Bahnsen se posicionasse diante da metafísica da vontade de Schopenhauer de modo semelhante à relação entre a monodologia leibniziana e o monismo substancial de Espinosa ${ }^{13}$. Mas ao invés de uma monodologia, Bahnsen desenvolve uma henadologia. Cada "henada" (Henade) seria um ato de vontade distinto com um caráter próprio. Daí o vínculo entre uma fenomenologia da vontade e uma caracteriologia. A concepção de caráter em Bahnsen, entretanto, seguirá uma linha diferente da teoria schopenhaueriana do caráter, pois ao invés de "desmembrar caracteres anatomicamente ou de fragmentálos analiticamente", trata-se "apenas de esforçar-se por entendê-los - mas a partir daquilo que para a maioria aparece exatamente como o absolutamente incompreensível: a contradição interna de seu ser próprio - como aquilo que, visto de perto, não pode faltar a nenhum caráter verdadeiro"14.

A vontade cindida em si mesma conhecerá na categoria do trágico sua qualidade fundamental, pelo fato de ser, apesar de suas duas metades contrapostas (uma que quer e outra que não quer) uma só vontade (enquanto caráter individual).

12 Vale a pena dizer aqui que para Bahnsen não há propriamente uma lógica dialética, isto é, uma lógica que aceitaria o conceito de contradição. Para Bahnsen, a lógica é a lógica clássica, por isso, a realidade, perpassada pela contradição é, em si mesma, ilógica. A contradição é um princípio "antilógico". 13 Cf. MÜLLER-SEYFARTH, W. Metaphysik der Entropie, p. 61-62.

14 BAHNSEN, J. Wie ich wurde was ich ward, p. 185. 
Será justamente a categoria do belo que tenta resgatar a vontade de sua cisão essencial, mas isso apenas no plano da idealidade. Portanto, a vontade conhece no trágico seu próprio dilaceramento e no belo procura escapar dele momentaneamente, o que só é possível por meio de um esquecimento do real e um recalcamento da realidade efetiva, uma espécie de "haxixe da alma" (Seelenhaschisch). Diferentemente se relaciona o humor em relação ao trágico, pois ao invés de se iludir como o belo em relação à autocontradição da vontade consigo mesma se desapega do sofrimento sem negá-lo. No humor, o intelecto consegue apreender o grotesco e o cômico da existência dissociando-se do sofrimento e atingindo a completa autodeterminação. Enquanto o belo oferece a aparência em forma de verdade, o humor apresenta a verdade em forma de aparência. Por isso, o humor aparecerá como o ápice da vida espiritual e como a sabedoria completa, aquela que apenas lança um olhar de desprezo irônico em relação a um mundo que não está destinado a qualquer conciliação: "o humor resulta tanto mais efetivo quanto mais claramente transparece a cabeça de Medusa do pessimismo por trás do louco que ri”'15.

É com a perspectiva do humor que Bahnsen irá se contrapor às soteriologias do pessimismo filosófico (de Schopenhauer a Hartmann, passando por Mainländer). Para compreender esse último e eseencial ponto do pessimismo absoluto de Bahnsen vale a pena como conclusão desta conferência traçar um breve paralelo com a concepção do trágico em Schopenhauer.

Como se sabe, a metafísica do belo de Schopenhauer tem como função apresentar as ideias, uma forma de conhecimento superior em grau de clareza e objetividade em relação ao conhecimento baseado no princípio de razão, o conhecimento ordinário que é servo da vontade do qual faz parte também a ciência. As artes, por sua vez, procuram apresentar uma forma de conhecimento independente do princípio de razão e do serviço da vontade, em que as ideias são expostas em graus cada vez mais elevados de objetidade: das artes plásticas que apresentam as manifestações das forças mais básicas da natureza até a música que apresenta já não mais as ideias mas a própria vontade. Cabe à arte poética, porém, apresentar a ideia de humanidade e representar, assim, a luta da vontade com ela mesma tal como se manifesta nos conflitos humanos. E dentro da arte poética um

15 BAHNSEN, J. Das Tragische als Weltgesetz und der Humor als ästhetische Gestalt des Metaphysischen, p. 108. 
lugar especial cabe à tragédia, a "forma superior do gênio poético" e que tem como tema o espetáculo de um grande infortúnio apresentando assim o conflito da vontade consigo mesma (der Widerstreit des Willens mit sich selbst). "Na tragédia, é o lado terrível da vida que nos é apresentado, a miséria da humanidade, o reino do acaso e do erro, a queda do justo, o triunfo do malvado; coloca-se assim, sob nossos olhos o caráter do mundo que se choca diretamente com nossa vontade" ${ }^{16}$. Como representação maxima desse conflito inerente à vontade e visível em seu mais alto grau de objetivação, a visão profunda proporcionada pela tragédia é a de que "o que o herói expia não são seus pecados pessoais, mas antes o pecado original, isto é, a culpa da própria existência"17.

A referência ao tema do "pecado original" já demonstra o vínculo entre a concepção schopenhaueriana do trágico e sua soteriologia. À tragédia cabe uma função por assim dizer pedagógica de transmitir o conhecimento sobre o aspecto terrível da vida e da necessidade de redenção. Ela nos prepara para o caminho da redenção:

Nosso prazer na tragédia [Trauerspiel] não pertence ao sentimento do belo [Gefühl des Schönen], mas ao do sublime [Gefühl des Erhabenen]. Sim, ele é, de fato, o mais alto grau deste sentimento. Assim, a visão do sublime na natureza permite que nos desviermos do interesse da vontade, a fim de nos comportarmos de uma maneira puramente intuitiva. Por isso, a catástrofe trágica nos desvia da vontade de viver [Willen zum Leben]. Assim, na tragédia, o lado terrível da vida nos é apresentado: o choro e a lamentação da humanidade, o domínio do acaso e do erro, a queda dos justos, o triunfo dos maus. E então aquele aspecto do mundo é trazido diante de nossos olhos, e ele se opõe diretamente à nossa vontade. Nessa visão nos sentimos convidados a evitar a nossa vontade de viver e nunca mais querer [wollen] e amar [lieben]. Mas, precisamente dessa forma, tornamo-nos conscientes de que ainda resta em nós algo diferente e que não proporciona um conhecimento positivo, mas apenas um negativo, como aquilo que não quer a vida. Assim como o acorde da sétima exige o acorde fundamental, assim como a cor vermelha exige a verde, e até mesmo a produz no olho, de modo análogo, cada tragédia exige uma existência de um tipo totalmente diferente, um mundo diferente, o conhecimento que só pode sempre ser dado a nós só apenas indiretamente, que se dá aqui por tal demanda, conforme já indiquei. No momento da catástrofe trágica, ficamos convencidos mais claramente do que nunca que a vida é um 
pesadelo do qual temos que acordar ${ }^{18}$.

Não se pode dizer que Bahnsen vá se opor a essa concepção do trágico. Para ele de fato a tragédia revela a "contradição da vontade consigo mesma" e é um momento revelador sobre o sentido ou a falta de sentido de existência ${ }^{19}$. Ocorre, porém, que para Bahnsen essa visão não exige pensar num outro tipo de existência, pois seu imanentismo absoluto não permite ver nada além do que se dá a conhecer neste mundo. Qualquer esperança de encontrar paz e conciliação é frustrada, devido às características real-dialéticas da vontade autocindida. Como a autocontraditoriedade da vontade é algo real e não meramente ideal, um fato e não um momento, constituindo portanto o núcleo metafísico inalterável da realidade, não se dá a possibilidade de superação da contradição, nem de conciliação e tampouco redenção.

A ideia de "negação da vontade por si mesma" é vista como algo inócuo, como um tipo de idealismo doentio que exige terapia. A crença na possibilidade de liberação do círculo contraditório da vontade autocindida é vista como um ímpeto juvenil, finalmente vencido pela maturidade do humor: "o humor aparece como a incapacidade de uma negação efetiva, que advém a si mesma e, por consequência, se resigna sobre a possibilidade de uma autonegação ideal"20. É pela rejeição de qualquer perspectiva conciliadora ou redentora que a filosofia de Bahnsen será caracterizada como "pessimismo absoluto", assim chamada pelo próprio autor para quem um "pessimismo conseqüente como tal deve proclamar a absoluta falta de salvação" ${ }^{21}$. A perspectiva da redenção, mesmo se compreendida de maneira mais decidida como uma via para o Nada (como em Hartmann e Mainländer) é rejeitada

\footnotetext{
18 SCHOPENHUAER, A. WWV II/MVR II, cap. 37. Em seu belo livro intitulado O nascimento do trágico - de Schiller a Nietzsche (Rio de Janeiro: Jorge Zahar, 2006), Roberto Machado interpreta essa passagem afirmando que esse "mundo de uma existência totalmente diferente" só pode ser o mundo da própria vontade (cf. p. 191). Interpreto, porém, em sentido contrário: o que se dá a ver na tragédia é justamente a possibilidade de um outro mundo para além daquele circunscrito pela afirmação da vontade de viver. Este é o sentido moral da existência para Schopenhauer: a compreensão de que é necessário deixar de querer esta vida para trilhar o caminho da redenção.

19 Vale mencionar que outro filósofo, ainda em sua juventude, e nesse sentido se inserindo na escola schopenhaueriana em sentido lato, também iniciará sua reflexão a partir de uma reelaboração do conceito de trágico. Tal não é outro senão Friedrich Nietzsche, com quem Bahnsen entendia compartilhar alguns pontos de contato, a ponto de escrever em uma carta dirigida ao autor de O nascimento da Tragédia em 22 de fevereiro de 1878 : "Se não quero privar-me de toda compreensão do trágico, eu deveria procurar, por assim dizer por necessidades domésticas, um outro conceito do trágico e o compreendi, como mostra meu escrito para o jubileu da Universidade de Tübingen, de modo mais metafísico, ou, se o senhor quiser, prático, como exclusivamente estético e histórico-artístico. Mas fora esta fundamental divergência, restam entre nós, creio, suficientes pontos de contato, mesmo pontos verdadeiros e próprios de coincidência das opiniões principais". Cf. FAZIO, D. Ein Begriff des Tragischen "zum Hausbedarf". Julius Bahnsen schreibt an Friedrich Nietzsche. In: L. Hühn u. P. Schwab (orgs). Die Philosophie des Tragischen. Schopenhauer, Schelling, Nietzsche, pp. 623-636).

20 BAHNSEN, J. Das Tragische als Weltgesetz und der Humor als ästhetische Gestalt des Metaphysischen, p. 124.

21 BAHNSEN, J. Der Widerspruch im Wissen und Wesen der Welt, II, p. 482.
} 
por Bahnsen também porque o mundo já é compreendido por este último como nada, portanto não pode tornar-se diferente daquilo que já é, e a existência é caracterizada antes como "niilência" $\left(\right.$ Nihilenz) ${ }^{22}$.

\section{Referências bibliográficas}

BAHNSEN, Julius. Beiträge zur Charakterologie: mit besonderer Berücksichtigung pädagogischer Fragen. Leipzig: Brockhaus, 1867.

Das Tragische als Weltgesetz und der Humor als ästhetische Gestalt des Metaphysischen. Berlin: VanBremen, 1995.

. Der Widerspruch im Wissen und Wesen der Welt. Princip und Einzelbewährung der Realdialektik. 2 Vols., Berlim, 1880 e Leipzig, 1882. Reeditado por W. H. Müller-Seyfarth. Zurique-Nova Yorque: Olms, 2003, 2 vols.

Mosaiken und Silhouetten. Charakterographische Situations - und Entwicklungsbilder. Berlin: VanBremen, 1995.

. Lo trágico como ley del mundo y el humor como forma estética de lo metafísico. Tradução de Manuel Pérez Cornejo. Universitat de València, 2015.

Wie ich wurde was ich ward. Nebst anderen Stücken aus dem Nachlass des Philosophen. (Hrsg.). R. Louis, München, 1905; segunda edição: (Hrsg.) A. Ruest, Leipzig, 1931.

Zum Verhältnis zwischen Wille und Motiv. Eine metaphysische Voruntersuchung zur Charakterologie. «Lauenburger Programmabhandlung», Danzig, 1869; Stolp und Lauenburg i. P., 1870.

BERNHARD, Wolfram. Schopenhauer und die moderne Charakterologie. SchopenhauerJahrbuch, 44 (1963), pp. 25-133.

CIRACI, Fabio; FAZIO, D. M.; KOßLER, M. Schopenhauer und die Schopenhauer-Schule. Würzburg: Königshausen \& Neumann, 2009.

FAZIO, Domenico M. La scuola di Schopenhauer: i contesti. In: La scuola di Schopenhauer: testi e contesti. A cura del Centro interdipartimentale di ricerca su Arthur Schopenhauer e la sua scuola dell'Università del Salento. Lecce: Pensa Multimedia, 2009.

Nietzsche e il pessimismo post-schopenhaueriano: Hartmann, Mainländer e

Bahnsen. In: La passione della conoscenza. Studi in onore di Sossio Giametta. A cura del Centro interdipartimentale di ricerca su Arthur Schopenhauer e la sua scuola dell'Università del Salento. Lecce: Pensa Multimedia, 2010, pp. 161-184 (Schopenhaueriana, 5).

. Ein Begriff des Tragischen "zum Hausbedarf". Julius Bahnesn schreibt an Friedrich Nietzsche. In: L. Hühn u. P. Schwab (Orgs). Die Philosophie des Tragischen. Schopenhauer, Schelling, Nietzsche. Berlin - New York: Walter de Gruyter, 2011, pp. 623-636.

HÜHN, L.; SCHWAB, P. (Orgs.) Die Philosophie des Tragischen. Schopenhauer, Schelling, Nietzsche. Berlin: Walter de Gruyter, 2008.

HEYDORN, Heinz-Joachim. Julius Bahnsen. Eine Untersuchung zur Vorgeschichte der modernen Existenz. Gòttingen-Frankfurt a. M., 1953.

INVERNIZZI, G. II pessimismo tedesco dell'Ottocento. Schopenhauer, Hartmann, Bahnsen e Mainländer e i loro avversari. Firenze: La Nuova Italia, 1994.

LÜTKHAUS, Ludger. Nichts: Abchied vom Sein, Ende der Angst. Frankfurt am Main: Zweitausendeins, 2007.

MACHADO, Roberto. O nascimento do trágico - de Schiller a Nietzsche. Rio de Janeiro: Jorge Zahar, 2006.

MÜLLER-SEYFARTH. Metaphysik der Entropie. Berlin: VanBrenen Verlagsbuchhandlung, 2000.

22 Idem, I, p. 432 
SCHOPENHAUER, A. Sämtliche Werke. Editadas e comentadas criticamente por Arthur Hübscher. Wiesbaden: F. A. Brockhaus, 1972, 7 vols. . Gesammelte Briefe. Hrsg. von A. Hübscher. Bonn: Bouvier, 1987.

Sobre o fundamento da moral. Tradução de Maria Lúcia Cacciola. São Paulo, Martins Fontes, 1995.

- O mundo como vontade e como representação. Tradução de Jair Barboza. São Paulo: Unesp, 2005. - Sobre a ética. (Capítulos 8 - 15 de Parerga e Paralipomena de Arthur Schopenhauer). Organização e tradução de Flamarion C. Ramos. São Paulo: Hedra, 2012.

Recebido: 01/12/15

Received: 12/01/15

Aprovado: 20/12/15

Approved: 12/20/15 